Regular Paper

\title{
Magnetic Properties and Heat-treatment Conditions of Permanent Magnet Wires Produced by Spinning Method in Rotating Liquid
}

\author{
Takashi TODAKA ${ }^{* 1}$, Subaru MATSUMURA*1 and Masato ENOKIZONO*1
}

\begin{abstract}
This paper presents magnetic properties of permanent magnet wires developed for applications of micro magnetic actuators. Nd-Fe-B and Sm-Co permanent magnets have been contributed to improve efficiency of electrical machines and magnetic actuators and to miniaturize their size and weight. Recently use of Nd-Fe-B based permanent magnets in micro machines is also paid attention to improve moving performance such as increasing torque and reducing energy losses. Our target is producing a $0.2 \mathrm{~mm}$ diameter wire-shaped permanent magnet directly by using a spinning method in rotating liquid for a medical application. In this paper, the magnetic properties of $\mathrm{Nd}-\mathrm{Fe}-\mathrm{B}$ and Sm-Co based permanent magnet wires developed with different nozzle orifice size $(0.1 \mathrm{~mm}, 0.2 \mathrm{~mm}$ and $0.3 \mathrm{~mm}$ in diameter) are discussed. The result shows that the coercive force of the wire samples made by using the nozzle whose orifice sizes is $0.1 \mathrm{~mm}$ was improved
\end{abstract}

Keywords: permanent magnet, wire, Nd-Fe-B, Sm-Co, coercive force, spinning method in rotating liquid.

(Received: 31May 2012, Revised: 10 June 2013)

\section{Introduction}

Well known as rare earth magnets, neodymium iron boron (Nd-Fe-B) magnets and samarium cobalt magnets (Sm-Co) are alloys of the lanthanide group of elements. The rare earth magnets are the most advanced commercialized permanent magnet materials from 1980's to today. The excellent quality of these magnets contributed to develop high-efficiency and small-sized home electrical appliance. The main applications were for electric machines as one of the energy saving technologies [1].

In recent years, applications of the rare earth magnets have been widened to micro machines [2]. The micro machines are used in a lot of situations, for example, optical system, information technology, medical treatment, well being and amusement or education. The way of being used the permanent magnets is simply as a source of static magnetic field and wireless driving force, and so on. We have paid our attention to a source of wireless driving force for a medical application, and in this purpose, very small permanent magnets have been produced from a lump of permanent magnets.

In this research, we tried to produce a fine permanent magnet directly from mother alloy by using the spinning method in rotating liquid. Our goal is establishment of a production method of $0.2 \mathrm{~mm}$ diameter and $2 \mathrm{~mm}$ length permanent magnet. The small-sized magnet will be attached at the top of a guide wire, and inserted it into a blood vessel for medical treatment. The direction of the top magnet can be controlled with

\footnotetext{
Correspondence: T. Todaka, Department of Electrical and Electronic Engineering, Faculty of Engineering, Oita University, 700 Dannoharu, Oita 870-1192, Japan email: todaka@oita-u.ac.jp

${ }^{* 1}$ Oita University
}

an external magnetic field produced by an electric magnet and wireless navigation becomes possible under monitoring with a real-time magnetic resonance imaging (MRI) [3].

In this paper, the magnetic properties and heattreatment conditions of the Sm-Co based and Nd-Fe-B based permanent magnet wires are made clear.

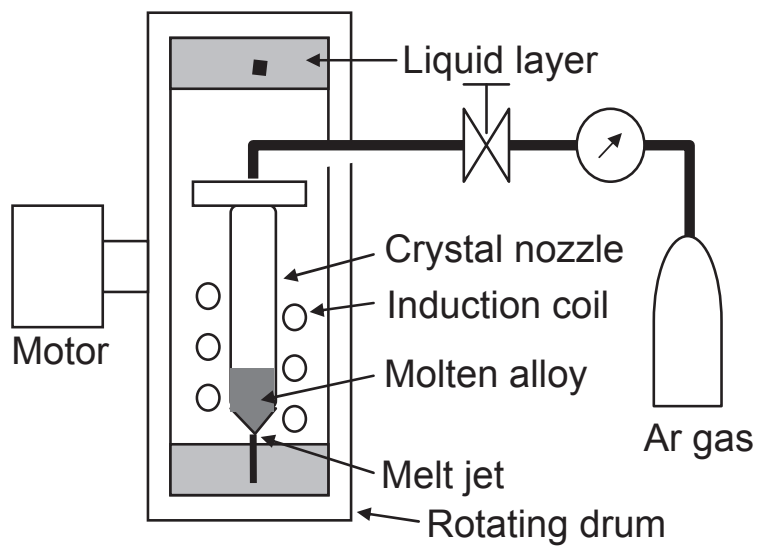

Fig. 1. Schematic view of the spinning system in rotating liquid

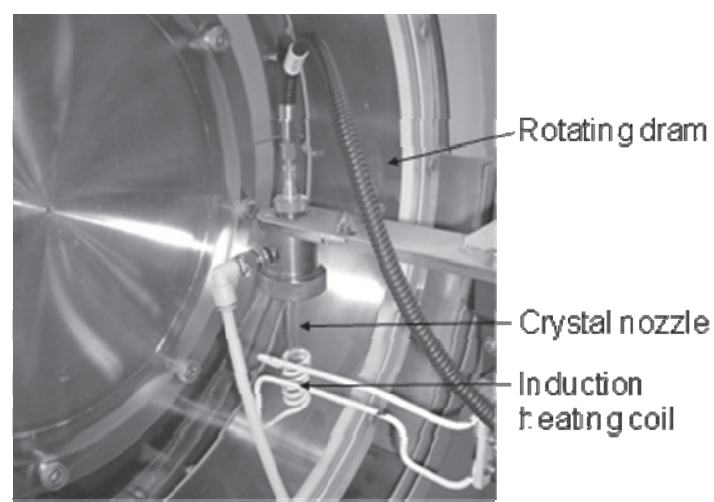

Fig. 2. Photograph of the durum and induction coil. 


\section{Sample Production and Evaluation Method}

\subsection{Production Method of Samples}

In this study, we tried to produce thin permanent magnets with the spinning method in rotating liquid [4, 5]. Fig. 1 shows the schematic view of the spinning system in rotating liquid and Fig. 2 shows the photograph. The mother alloys were produced by an arc furnace in argon atmosphere. The production procedure of a wire is as follows: Firstly, we have poured cooling liquid inside the rotating drum, which can keep liquid layer on inner wall by the centrifugal force. Secondly, we have put about $2 \mathrm{~g}$ mother alloys into a quartz nozzle and set the nozzle to approach closely to the liquid layer surface. Then the mother alloy is melted by induction heating and injected into the coolant through the orifice at the nozzle top with argon gas pressure. Because the symmetrical liquid-pressure is given on melt jet, wires can be formed.

We have produced the Nd-Fe-B and Sm-Co based wires by the spinning method in rotating liquid. In producing the wires, we used 0.75 mass $\%$ antioxidant solution (W-75) for the coolant. Also we prepared three kinds of nozzle orifice size to clarify effect of cooling rate on the coercive force characteristics: $0.1 \mathrm{~mm}, 0.2$ $\mathrm{mm}$ and $0.3 \mathrm{~mm}$ in diameter.

\subsection{Evaluation Method of Samples}

In the characterization, hysteresis loops and thermalmagnetic properties were measured with a vibrating sample magnetometer (VSM). The direction of the supplied magnetic field was parallel to the longitudinal direction of the wire samples. Furthermore transformation points of the samples were measured with a differential scanning calorimeter (DSC). Platinum and alumina pans were used for the sample holder and reference, respectively. The increasing rate of temperature was $20{ }^{\circ} \mathrm{C}$ per minute. In the phase analysis we used an X-Ray diffraction (XRD) system. The wires were analyzed as it is and after powdered. The observation of cross section of wires was also performed with a scanning electron microscope (SEM).

\subsection{Produced Samples}

Firstly we examined Nd-Fe-B wires produced with the different nozzle orifice. The composition of the mother alloy was $\mathrm{Nd}_{6} \mathrm{Fe}_{79} \mathrm{~B}_{15}$ at \%. The other conditions are summarized in Table 1. Secondly we newly tried to produce $\mathrm{SmCo}_{5}$ wires. The composition of the mother alloy was $\mathrm{Sm}_{16.7} \mathrm{Co}_{83.3}$ at\%. Table 2 shows the production conditions of $\mathrm{SmCo}_{5}$ wires.

\section{Measured Results}

\section{$3.1 \mathrm{Nd}-\mathrm{Fe}-\mathrm{B}$ Wires}

Fig. 3 shows the coercive force depending on heattreatment of the wires produced with the different nozzle orifice. The coercive forces of as-span samples were also shown in Fig. 3 for comparison. In the heattreatment, the samples were hearted up to $600{ }^{\circ} \mathrm{C}$ with a rate of $4.5^{\circ} \mathrm{C} / \mathrm{min}$ in vacuum $\left(6 \times 10^{-3} \mathrm{~Pa}\right)$ in an infrared lamp heating system and the temperature was kept for 1 through 4 hours and cooled down in the chamber. The heart-treatment temperature was decided to be $600{ }^{\circ} \mathrm{C}$ because the transformation was observed around $640{ }^{\circ} \mathrm{C}$ in DSC analyses and the coercive force deteriorated by heating over this transformation temperature [4].

The coercive forces of the sample produced with 0.1 $\mathrm{mm}$ orifice-sized nozzle were large in comparison with the other ones. The largest coercive force about 500Oe was obtained with the 2-hour heat treatment. The coercive forces of the samples produced with 0.2 and $0.3 \mathrm{~mm}$ orifice-sized nozzles were improved with 1hour heat treatment. As a result, we can summarize that the smaller orifice size is suitable to improve the coercive forces of the wire samples, because the cooling rate can make larger and the crystal grain size can minimize to be a suitable dimension.

Figs. 4 (a) and (b) show the cross-sectional photographs with SEM of the wire samples produced with 0.1 $\mathrm{mm}$ and $0.2 \mathrm{~mm}$ orifice-sized nozzle, respectively. The crystal grain sizes were around 10 micrometer. Because the cooling rate of the in-rotating liquid spinning process is slower, the produced wires were not amorphous as cast.

Table 1 Conditions used in production of Nd-Fe-B wire

\begin{tabular}{|c|c|c|c|}
\hline $\begin{array}{c}\text { Orifice size } \\
{[\mathrm{mm}]}\end{array}$ & $\begin{array}{c}\text { Ar gass Presser } \\
{[\mathrm{MPa}]}\end{array}$ & $\begin{array}{c}\text { Revolution } \\
\text { speed }[\mathrm{m} / \mathrm{s}]\end{array}$ & $\begin{array}{c}\text { Output } \\
\text { current } \\
{[\mathrm{A}]}\end{array}$ \\
\hline 0.1 & 0.32 & 5.24 & 12 \\
\hline 0.2 & 0.22 & 5.24 & 12 \\
\hline 0.3 & 0.18 & 5.24 & 12 \\
\hline
\end{tabular}

Table 2 Conditions used in production of Sm-Co wire

\begin{tabular}{|c|c|c|c|}
\hline $\begin{array}{c}\text { Orifice size } \\
{[\mathrm{mm}]}\end{array}$ & $\begin{array}{c}\text { Ar gas presser } \\
{[\mathrm{MPs}]}\end{array}$ & $\begin{array}{c}\text { Revolution } \\
\text { speed [m/s] }\end{array}$ & $\begin{array}{c}\text { Output } \\
\text { current } \\
{[\mathrm{A}]}\end{array}$ \\
\hline 0.1 & 0.32 & 6.54 & 12 \\
\hline 0.2 & 0.22 & 7.20 & 12 \\
\hline 0.3 & 0.20 & 7.20 & 12 \\
\hline
\end{tabular}

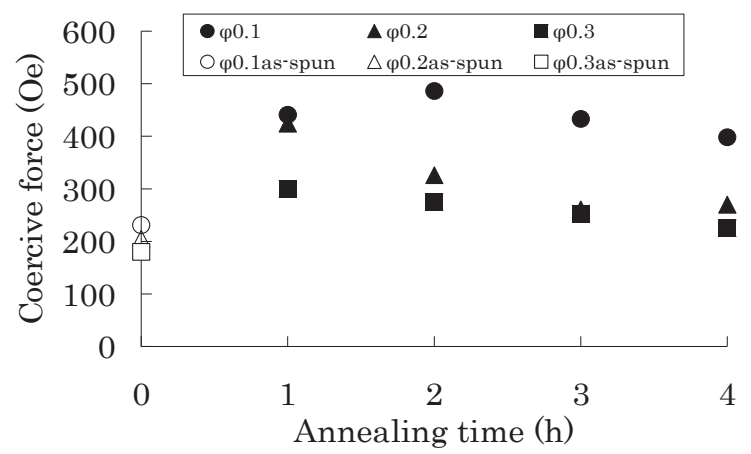

Fig. 3. Coercive force depending on heat-treatment of wire samples produced with the different nozzle orifice. 


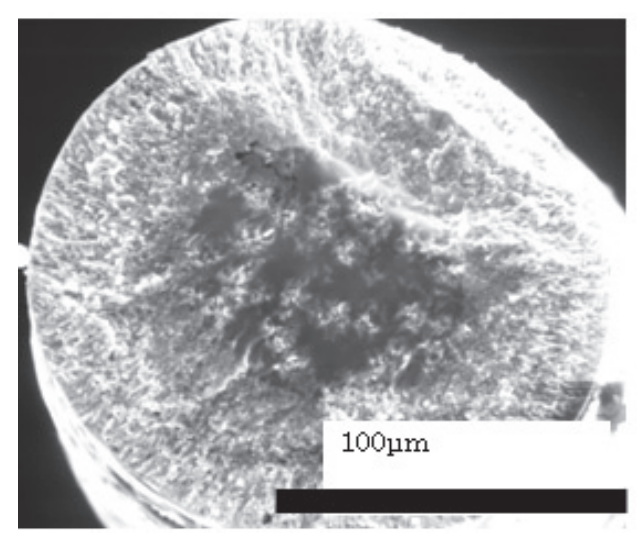

(a) $0.1 \mathrm{~mm}$ orifice-sized nozzle

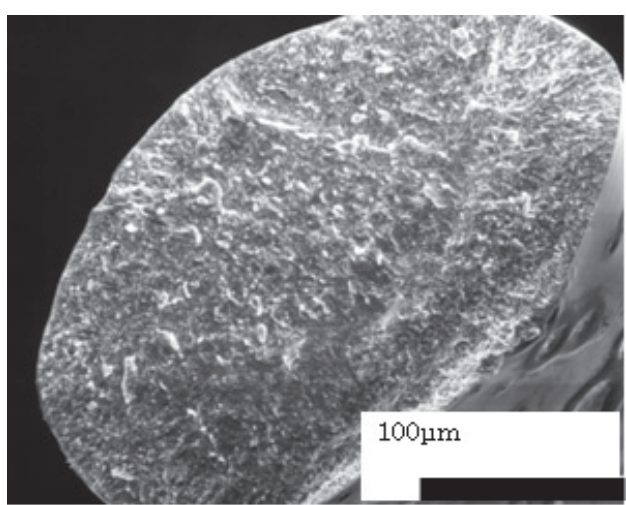

(b) $0.2 \mathrm{~mm}$ orifice-sized nozzle

Fig. 4. Cross sectional SEM images of $\mathrm{Nd}_{6} \mathrm{Fe}_{79} \mathrm{~B}_{15}$ at.\% wire samples produced by using nozzles of $0.1 \mathrm{~mm}$ orifice (a) and $0.2 \mathrm{~mm}$ orifice (b).

As shown in Fig. 4, the roundness of the wire produced with $0.1 \mathrm{~mm}$ orifice-sized nozzle was well and it was 0.92 (the major axis: $0.167 \mathrm{~mm}$, minor axis: $0.153 \mathrm{~mm})$. As for the wire produced with $0.2 \mathrm{~mm}$ orifice-sized nozzle, the roundness was 0.60 (the major axis: $0.377 \mathrm{~mm}$, minor axis: $0.226 \mathrm{~mm}$ ). The roundness increased with decreasing the orifice size. The diameters were larger than the orifice sizes.

\subsection{Sm-Co Wires}

Since $\mathrm{SmCo}_{5}$ is also one of candidates to mount on top of guide wires, we tried to produce wires. Fig. 5 shows the coercive force of the produced Sm-Co based wires as span. As shown in this figure, the coercive force increased as the orifice size of nozzles became smaller. This tendency is similar to one of Nd-Fe-B wires mentioned in the above and the reason can be considered that the cooling rate of the mother alloy increases as the orifice size becomes smaller. Because the crystal size depends on the cooling rate and it becomes smaller as the orifice becomes smaller, the coercive force can be improved by minimizing the crystal size to be a suitable one.

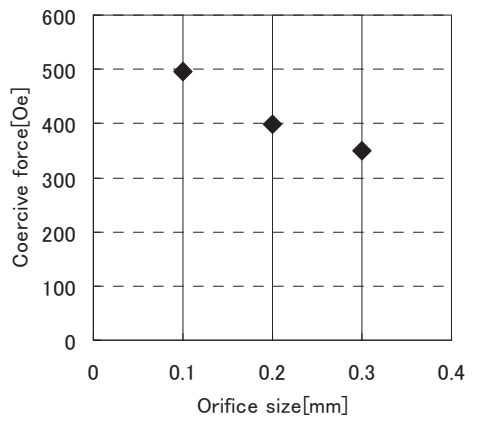

Fig. 5. Relationship between the coercive force of SmCo wires as span and the orifice size of nozzles.

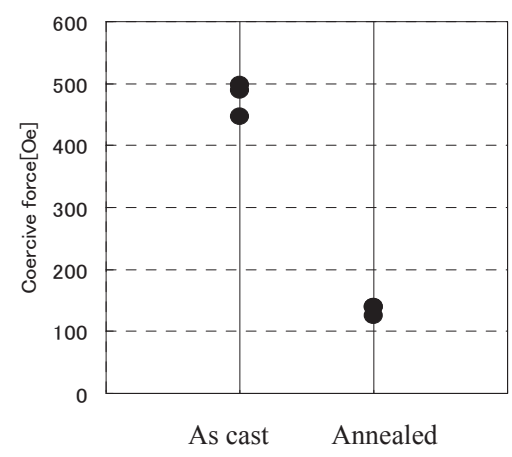

Fig. 6. Coercive force of Sm-Co wire produced with 0.1 $\mathrm{mm}$ orifice-sized nozzle before and after heat-treatment.

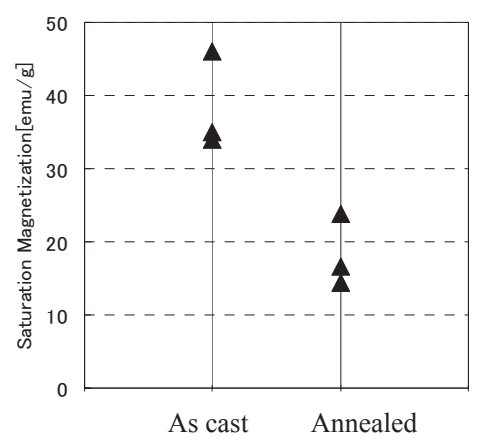

Fig. 7. Saturation magnetization of Sm-Co wire produced with $0.1 \mathrm{~mm}$ orifice-sized nozzle before and after heat-treatment.

Figs. 6 and 7 show the coercive force and the saturation magnetization of the wire samples produced with the $0.1 \mathrm{~mm}$ orifice-sized nozzle before and after heattreatment. In the heat-treatment, the sample was heated up to $1000{ }^{\circ} \mathrm{C}$ with a rate of $40{ }^{\circ} \mathrm{C} / \mathrm{min}$, and the temperature was kept 1 hour, and then cooled to be $500{ }^{\circ} \mathrm{C}$ within $10 \mathrm{~min}$ and cooled again to be room temperature during 3 hours. The coercive force decreased after the heat-treatment for all the cases. The reason can be considered that the $\mathrm{Sm}_{2} \mathrm{Co}_{7}$ phase appeared in the cooling process [6]. The coercive force as cast was larger than that of Nd-Fe-B wires, however the hearttreatment was very complicated to obtain $\mathrm{SmCo}_{5}$ phase.

Fig. 8 shows the X-ray diffraction patterns of the mother alloy and the wire sample produced with $0.1 \mathrm{~mm}$ 
orifice-sized nozzle. Fig. 8 (b) was measured as it is by putting the short wires side by side. Fig. 8 (c) was measured after powdered with a mill. As shown in Fig. 8 (b), the surface of the wire was almost $\mathrm{Sm}_{2} \mathrm{O}_{3}$ and it is caused by oxidation in the manufacturing process of inrotation liquid spinning method. As for Fig. 8 (c), inside of the wire sample, we can observed mainly $\mathrm{SmCo}_{5}$ and $\mathrm{Sm}_{2} \mathrm{Co}_{7}$ phases and this pattern was quite similar to that of mother alloy shown in Fig. 8 (a). It can be considered that the sample surface was only oxidized in the nozzle at hearing process during the induction heating or in coolant during spinning process.

Fig. 8 shows the cross sectional SEM images of the Sm-Co wire produced with the $0.1 \mathrm{~mm}$ orifice-sized nozzle. As shown in this photograph the roundness was quite good (about 0.80 ) and the crystal grain sizes were around 10 micrometer.

\section{Conclusion}

In this paper, the magnetic properties of $\mathrm{Nd}-\mathrm{Fe}-\mathrm{B}$ and Sm-Co based permanent magnet wires produced with different nozzle orifice size were presented. The coercive force increased as the orifice size of nozzles became smaller. The coercive forces of the sample produced with $0.1 \mathrm{~mm}$ orifice-sized nozzle were large in comparison with the other ones. The reason can be considered that the cooling rate of the mother alloy increased as the orifice size became smaller.

After the heat-treatments, the coercive forces of the $\mathrm{Nd}-\mathrm{Fe}-\mathrm{B}$ magnet wires were improved, however we could not obtain any improvement for the Sm-Co wires. It is known that the eutectoid decomposition into $\mathrm{Sm}_{2} \mathrm{Co}_{17}$ and $\mathrm{Sm}_{2} \mathrm{Co}_{7}$ occurs around $800{ }^{\circ} \mathrm{C}$ when $\mathrm{SmCo}_{5}$ was slowly cooled from $800{ }^{\circ} \mathrm{C}[6]$. Therefore, existing $\mathrm{Sm}_{2} \mathrm{Co}_{7}$ phase becomes a nucleation site for an inverse magnetic domain and the coercive force deteriorates. Optimizing the heart-treatment condition for the $\mathrm{Sm}-\mathrm{Co}$ wires remains as a further problem to be solved.

\section{References}

[1] M. H. Walmer, J. F. Liu and P. C. Dent, "Current Status of Permanent Magnet Industry in the United States," Proc. The $20^{\text {th }}$ Int. Work. REPM, Vol. 20, pp. 1-6, 2008.

[2] K. Ishiyama, M. Sendoh, A. Yamazaki and K. I. Arai, "Magnetic Wireless Actuator for Medical Applications," J. Magn., Vol. 8, No. 1, pp. 74-78, 2003.

[3] M. Schiemann, R. Killmann, M. Kleen, N. Abolmaali, J. Finney and T. J. Vogl, "Vascular Guids Wire Navigation with a Magnetic Guidance System-Experimenta Results in a Phantom," Radiology, pp. 475-481, 2004.

[4] D. Yamamichi, T. Todaka and M. Enokizono, "Producing Microscopic Permanent Magnet with Rapid Cooling Method," J. JSAEM, Vol. 19, Supplement, pp. S57-S62, 2011.

[5] T. Todaka, D. Yamamichi, S. Matsumura and M. Enokizono, "Production of Thin Line Magnets by using Inrotating Liquid Spinning Method and Improvement of Their Coercive Force," J. JSAEM, Vol. 20, No. 1, pp.5358, 2012, (in Japanese).
[6] M. Honma and S. Sugimoto, "Magnetic Materials -Hard Magnetic Materials II-," J. Magn. Soc. of Japan, Vol. 25, No. 11, pp. 1580-1587, 2001, (in Japanese).

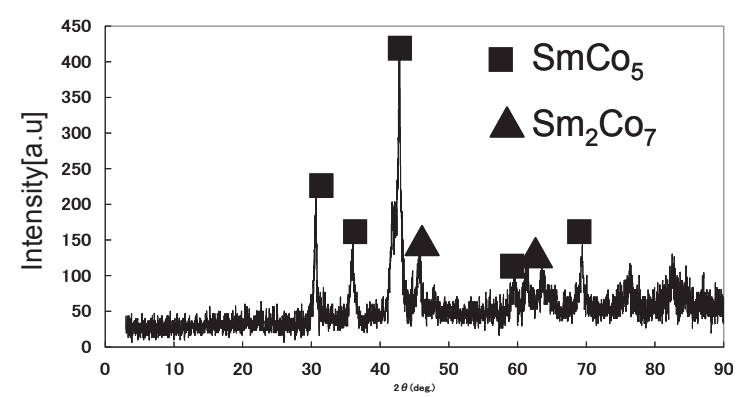

(a) Mother alloy

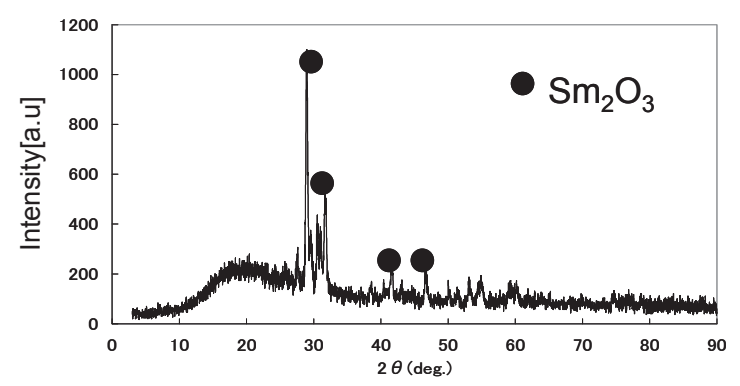

(b) Wire surface

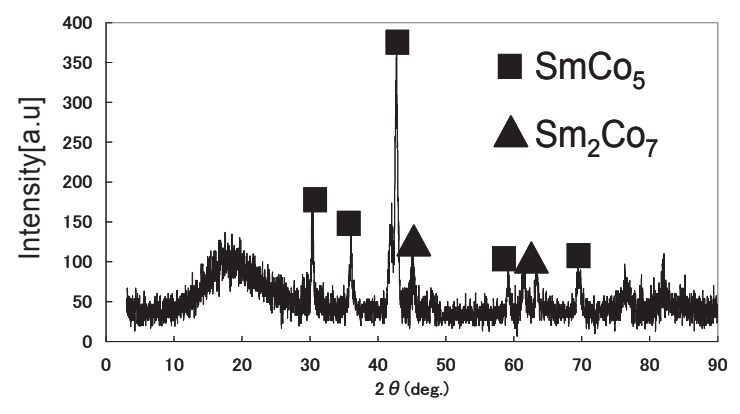

(c) Powdered wire

Fig. 8 X-ray diffraction patterns of the wire sample produced with $0.1 \mathrm{~mm}$ orifice-sized nozzle.

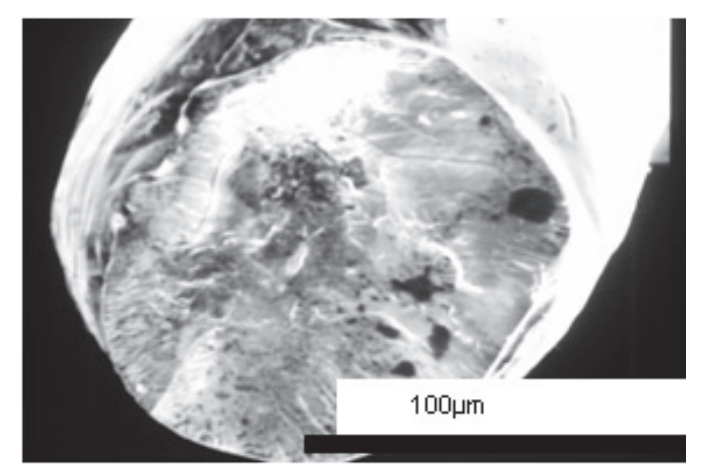

Fig. 9. Cross sectional SEM images of the Sm-Co wire sample produced with the $0.1 \mathrm{~mm}$ orifice-sized nozzle. 